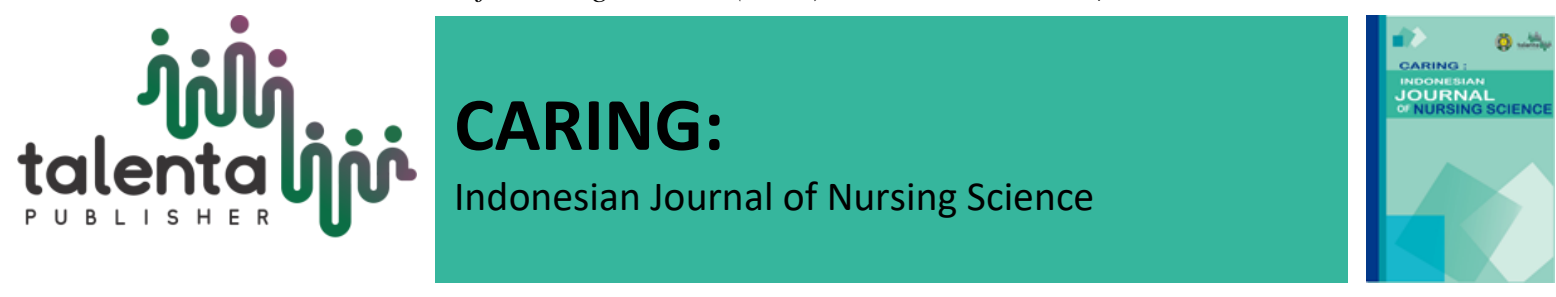

\title{
Mothers and Children Right and Need for Essential Services Accessibility in Communities
}

\author{
Khanitta Nuntaboot ${ }^{1}$, Nittaya Panngam ${ }^{2 *}$ \\ ${ }^{1,2}$ Faculty of Nursing, Khon Kaen University, Thailand
}

\begin{abstract}
Community play important role to enhance the accessibility to essential rights and services of mothers and children in community. This study utilizes the rapid ethnographic community assessment process (RECAP) to explore community potential for managing accessibility to rights and services of mothers and children in communities. The study was conducted in 8 sub-districts of 8 provinces in 4 regions nationwide. There are 146 informants recruited from purposive sampling include family members, community leaders, local leaders, health care providers, and social groups. Data were collected by the participated observation, in-depth interview, focus group discussion, as well as consultation using interview and focus group guidelines. Data were analyzed using content analysis and thematic analysis. The results reveal two parts include 1) sociocultural context of mothers and children which demonstrate need and way of life of pregnant women and child rearing; and 2) community managing to enhance essential right and service accessibility of mothers and children includes (1) managing fundamental right and services; (2) health services; (3) social welfare and community funds; (4) development safe and learning-enhanced environment; (5) educational services; (6) managing sources of information; and (7) caring based on cultural and traditional way. Based on this findings, national policy makers and relevant stakeholders could be utilizing for improvement prospective development and national policy to reinforce and strengthen community organizations contributing to health development of mothers and children.
\end{abstract}

Keywords: Rapid Ethnographic Community Assessment Process, Maternal Rights, Child

Rights, Services for Mother and Child, Service Accessibility, Community Management

Received 19 May 2020 | Revised 10 June 2020| Accepted 19 June 2020

\section{Introduction}

Children and women are a group of populations deserved to receive the protection of rights to access to essential welfares according to Millennium Declaration and the World Fit for Children Declaration without restrictions of ethnicity, class, gender, and socio-economic status. In particular, those who have difficulties in life should be provided with social security, and grow up maturely, as well as requiring to receive special assistance before and after birth in order to

*Corresponding author at: 123, Moo 16 Mittrapap Rd., Muang District, Khon Kaen 40002, Thailand. Corresponding e-mail: nittapa@kku.ac.th Copyright @ Published by Talenta Publisher, ISSN: 2580-6769 e-ISSN: 2580-829X Journal Homepage: https://talenta.usu.ac.id/IJNS 
enhance well-being in terms of nutrition, accommodations, accessibility to public health services, and essential welfares without restrictions of social, economic, political, and cultural status (UNICEF, 2008).

Thailand has continuously developed the system of caring for mothers and children for a long period of time through the integration among relevant agencies at a policy level, consisting of Ministry of Public Health, Ministry of Social Development and Human Security, Ministry of Interior, and Ministry of Education, aiming to devise the policies for protection of mothers and children's rights to access to various types of public welfare consistently (UNICEF, 2011). Also, the long-term policy for the year 2007-2016 on devising strategies for early childhood (Office of the Education Council, 2007), the National Health Security Act, B.E. 2545 (Secretariat of the House of Representatives, 2004), and the Determining Plans and Process of Decentralization Act, B.E. 2542 (Office of the Council of State, 2006) were announced and implemented. At an operational level, several activities have been carried out in compliance with the policies, for instance, health service centers, antenatal care services, training courses at parental schools, childbirth preparation courses, promotion of breastfeeding, promotion of child growth and development, and immunization (Netgrajang, Nuntaboot, \& Theerasopon, 2014). In addition, local administrative organizations and community organizations are in charge of enhancing development of early childhood, establishing child development centers in communities, encouraging involvement of parents and related persons, and allocating welfares and funds for those with specific need, such as elderly people, disabled people, and newborns (Jaitieng \& Nuntaboot, 2018). Even though multiple implementations established for those early childhood, some parent living in poor and near-poor households lacked of necessary service accessibility which effect to their child's nutritional status and development. In the fiscal year 2016, Thai government realized the importance of reducing social inequality and providing the opportunity for underprivileged children and women to access essential welfares in across the nations, so the government formulated the policy on social protection according to the integration plan for human lifespan development by providing subsidies for child rearing in impoverished and poverty-prone households during October 1, 2015 - September 30, 2016 in an amount of $400 \mathrm{baht} /$ person/month for 12 months. This program was financed by UNICEF and Thai Health Promotion Foundation (THPF) which expect to enhance children received highquality care, achieve age-appropriate development, as well as increase the opportunity to access to other rights systematically. As a consequence, children would grow up as high-quality populations in the society and make great contribution to future development of the country. To achieve the program's objective and monitor the effectiveness of the implementation, the agencies and community organizations play important. At an operational level, organizations in localities are required to involve in deciding to certify the application for subsidization for newborns in troubled families. This is regarded as the stimulation of mechanism in localities 
where the operations for caring for pregnant women and children aged 0-5 years has existed so as to enable them to learn and acknowledge their own roles and work methods (UNICEF, 2019). In order to evaluate the possibility of the policy deployment to maximize benefits for the target group, and propose to become one of strategies for efficient health development of mothers and children, the project by the coalition of research partners included Khon Kaen University and the Thai Health Promotion Foundation (THPF) were established. This complex multistakeholder arrangement increased the institutional challenges, it both consolidated broad ownership of the research process and expanded the collaboration among the relevant sectors in the community. This project led impact evaluation was designed to provide policy-level inputs for improving the program's effectiveness and efficiency so as to maximize the impact on key outcomes for young children. Likewise, this study was a part of the project conducted to monitor the operating process of subsidization project for child rearing, as well as to evaluate community potential for increasing accessibility to essential rights and services among mothers and children. Especially, this study focus to explore work and activities of community agencies and organizations for managing accessibility to essential rights and services of mothers and young children in communities. The results of the study would be provided critical evidence documenting to support decision-making and policy-based planning in relation to the implementation of long-term projects relying on existing resources, and help integrate the subsidization project for child rearing into social capital mechanisms in localities.

\section{Research Methods}

This qualitative research utilizes the rapid ethnographic community assessment process (RECAP) (Nuntaboot et al., 2013). It aims to explore the community potential in managing accessibility to rights and services of pregnant women and children aged 0-5 years in communities. The study had been conducted during October 2016 - September 2017. There were 8 sub-districts from 8 provinces which covered four regions of Thailand, namely, Nakhon Ratchasima, Ubon Ratchathani, Tak, Si Sa Ket, Mae Hong Son, Kalasin, Sa Kaeo, and Narathiwat were selected. Considering the criteria for choosing venues to be studied, it should be the area which outstandingly performed for assisting mothers and children in communities, having actively cooperation between agencies and organizations in communities, and pregnant women participating in the government subsidization project for child rearing. The informants were recruited by purposive sampling and snowball technique which consisted of community leaders, local leaders (village headmen and sub-district headmen), health care providers, family members of pregnant women, and social capitals relevant to maternal and child care in community.

The data were collected by the participant observation, in-depth interview, focus group discussion, as well as consultation using interview and focus group guidelines. In each venue, there were researchers and research assistants who had attended a qualitative study training 
program which utilized the rapid ethnographic community assessment process (RECAP) to conduct the research in communities, and had been experienced in training how to collect the data by the participant observation, in-depth interview, and focus group discussion. Moreover, the data were also collected by related literature review, such as the database of local administrative organizations, sub-district health promoting hospitals, and so on. The trustworthiness were verified as follows: (1) The data reliability was verified by the triangulation, method triangulation, investigator triangulation, and data triangulation; (2) The venue had been visited continuously and regularly so that the informants felt trust and gave the actual answered; (3) The participation in activities of each venue to indicate and affirm the data; and (4) The validation of data was conducted by the informant validation, member checking, the expert validation, and the comparative analysis. The data were analyzed by the content analysis and thematic analysis. Prior to the reliability test of the acquired data, the typology was conducted. In addition, this study passed the ethical review of human research by the Ethical Review Committee for Human Research, Khon Kaen University, under the project no. HE592118.

\section{Results and Discussion}

There were 146 informants participated in this study. Those informants were referred as the key actors who had significant roles for helping mothers and young children in community to access to essential services.

Based on Table 1 showed that there were four types of participants in community organizations and agencies consist of community leaders, local leaders, health care providers, family members of pregnant women, and social group relevant to maternal and child care in community.

\section{Table 1. The Characteristics of Informants}

\begin{tabular}{l|c|c}
\multicolumn{1}{c|}{ Informants } & Amount & Percentage \\
\hline Community leaders & & \\
\hline - Village health volunteers & 20 & $13.70 \%$ \\
\hline - Religious leaders & 2 & $1.40 \%$ \\
\hline Local leaders & & \\
\hline - village headmen & 12 & $8.30 \%$ \\
\hline - sub-district headmen & 1 & $0.68 \%$ \\
\hline - Officer in Provincial Administrative Organization (PAO) & 5 & $3.442 \%$ \\
\hline Health care providers & & \\
\hline - Health care providers in HPH & 2 & $1.37 \%$ \\
\hline Family members of pregnant women & & \\
\hline - pregnant women & 22 & $15.07 \%$ \\
\hline - family members of pregnant women & 18 & $12.33 \%$ \\
\hline - parent of pregnant women & 20 & $13.70 \%$ \\
\hline - relative of pregnant women & 2 & $1.37 \%$ \\
\hline - grandparent of pregnant women & 32 & $21.92 \%$ \\
\hline Social group relevant to maternal and child care in community & & \\
\hline - career group & 6 & $4.11 \%$ \\
\hline - care giver in child development center & 4 & $2.74 \%$ \\
\hline
\end{tabular}


The results of the study in 8 venues could be summarized as the analysis of the circumstance of caring for pregnant women and children aged 0-5 years, and the community potential in managing accessibility to essential services of mothers and children aged 0-5 years. The current finding comprised of 2 parts comprised 1) social and cultural context of mothers and child rearing; and 2) community managing to enhance the accessibility to essential rights and services of mothers and children.

Part one, social and cultural context of mothers and child rearing. The results regarding social and cultural context of mothers and child rearing could be explained with the circumstances of the way of life among pregnant women and women with children. These circumstances presented issues regarding requirements or need, self-management of communities, and conditions of accessibility to rights and services of mothers and children in communities.

The way of life of pregnant women and women with children revealed that pregnant women and mothers lived their lives under social and cultural context of communities that affected development, growth, rearing, and learning of children aged 0-5 years. It was found that pregnant women and women with children lived in 4 types of families and communities as follows: 1) Mutual support, this type focused on sharing as much as possible, for example, sharing milk and food, mutual assistance in child rearing, passing on clothing and child care equipment, and so on, due to good relationship between family members, including siblings or relatives, and neighbors. In addition, several communities formed a group for saving purpose, or established funds for mutual assistance, while offering welfares for mothers and newborns, and providing mothers with loan supports for occupation, extra income, and educational purposes; 2) Life full of "struggle", as child rearing incurred rather high expenses, wealthy families seemed not to be much effected, but poor families needed to struggle to earn a living for their families and children. As a result, the context of child rearing was varied, for example, requesting for assistance in child rearing from grandparents or relatives, as well as neighbors, when going out for working. The working period of mothers depended on the socio -economic status of families. Most employed mothers had to go back to work immediately after childbirth, possibly after 1 week, being unable to take a leave, while unemployed mothers had to rely on their families and relatives until they would find a job; 3) Family characteristics, types of family strongly affected child rearing. When husbands and wives lived together with parents of wives or parents of husbands, and especially in extended families which included elderly people, patients with chronic diseases, and disabled people, child rearing circumstance would have more conditions and restrictions; 4) Adherence to religious traditions and rules, from birth to death, child rearing was mainly associated with religious activities, especially in strict families, such as in case of Muslim families, newborns had to be bathed by Tok Bidan. As for Buddhist families, monks would do the naming traditions for newborns, as well as wrist tying ceremony, while women would lie by the fire after childbirth, as well as avoiding some foods, 
and providing mothers with nourishing herbs. In case of families of various tribes, such as Tai Yai, Hmong, Pa-o, Red Karen, Chinese Yunnan, and so on, they had the hair cutting ceremony for newborns, provided mothers after childbirth with special herbs, and so on. Such activities were not only family activities, but also the community practices. Participating in these activities also indicated the community membership. Therefore, low-income families had limitation in doing these activities due to expenses incurred in all activities.

In term of socio-cultural context of child rearing, four styles of child rearing are illustrated include 1) child rearing by parents, 2) child rearing by single father or single mother, 3) child rearing by child development centers, and 4) child rearing by relatives.

Part two, community managing to enhance the essential rights and services accessibilities of mothers and children. This part refers to the work and activities of social capitals which comprised community organizations, agencies, and social groups relevant to manage the accessibility to rights and services of pregnant women and children aged 0-5 years. There were seven parts of community works and activities comprising 1) managing fundamental rights and services; (2) health services; (3) social welfare and community funds; (4) development of safe and learning-enhanced environment; (5) educational services; (6) managing sources of information; and (7) caring based on cultural and traditional way.

Firstly, managing fundamental rights and services. This kind of service in communities were performed through the participation of organizations, public agencies, and people sector in communities to enable people in communities to access to public utilities, including mothers and children. The activities include: (1) water supply management by establishing water funds; (2) electricity management by local administrative organizations and public agencies; and (3) ensuring accessibility to sources of safe food by forming career groups and groups for originating food, such as home vegetable groups, fish feeding groups, housewife groups, and so O

Secondly, development health services, these activities aim to enhance accessibility to health services of mothers, pregnant women, and children aged 0-5 years. There are four groups of health services include:

1) Caring from folk philosophers such as local wisdom, midwives, folk healers, To-Imam, and Tok-Bidan. In case of pregnant women, postpartum women, newborns, and ill children, cultural way and religious ceremonies were applied to raising confidence in caring for mothers and children, as well as building relationships and enhancing warmth in families and communities, such as using herbal medicine for medical treatment, childbirth care, ensuring best birthing position, delivery of baby, postpartum massage, female circumcision, baby's first haircut, and so on. 
“.... People in the village and other villages gave respect in the same way. After childbirth, they usually took children to be sprayed with holy water and named by monks for blessings of life. Moreover, there were activities held to encourage children to learn traditions and religion, such as offering food to monks, praying, and so on. Novices who were students at Buddhist Scripture Schools also taught and led children to play games and do various activities..." (Ubon Ratchathani province)

2) Caring from volunteers, the services were provided included: (1) volunteering mothers and village health volunteers performed activities for promotion of pregnant women's health, gave advices about caring during pregnancy, took care of mothers and children after birth, as well as breastfeeding, nutrition assessment, children development, and surveillance of epidemic diseases; (2) EMS team members helped transfer patients in emergency cases, monitored pregnant women in emergency labor, emergency patients, and emergency child patients; (3) folk healers, herbal groups, massagers, home vegetable groups, exercise groups, elderly clubs, and elderly schools gave advices about food consumption and exercise by applying local wisdom, made up toys for promoting child development, and so on.

..." Herbal group formed the group to do herbal plantation, make up herbal compress balls, and provide medicinal bathing after birth. Herbal healers applied local wisdom to taking care of pregnant women before and after birth by using herbs... " (Mae Hong Son province)

3) Caring from health service centers. These activities were performed by local health service centers, including health promoting hospitals, community hospitals, or other health service units. The activities were established for pregnant women, children, and families continuously which cover health care, promotion of development, therapy and treatment, emergency cares, antenatal care, parental school program, childbirth preparation program, promotion of breastfeeding, promotion of child growth and development, and immunization. There are eight kinds of health services consisted of (1) proactive health services including caring for pregnant women, newborns, and postpartum mothers, antenatal care, developmental screening, promotion of age-related development, transferring cases of children with delayed development, surveillance of nutritional status, dental health, disease screening and surveillance, and disease screening and surveillance; (2) establishing the caring system to deal with acute, emergency, or chronic health problems, or primary assistance, such as ambulance service, assistance service in case of illness and difficulty; (3) training mothers and caregivers including establishing parental schools, educating about breast milk and child feeding, practicing skills of teachers and caregivers of child care and development centers regarding children nutritional status and dental health care, and so on; (4) developing capability of village health volunteers, family leaders, and volunteers in communities regrading monitoring antenatal care and pregnancy examination, assessment and promotion of growth and development, immunization, providing assistance in normal situations and emergency or accident cases, such as arranging activities or stimulating parents, providing assistance for those who had accidents from falling into water, fractures, food poisoning, and in case of acute, emergency, or chronic problems; (5) 
establishing monitoring system for vaccination of children; (6) coordinating and transferring to other agencies specialized in child care, such as schools for the blind, schools for the deaf, autistic centers, and so on; (7) coordinating with networks and agencies for supporting families with adolescent mothers ; and (8) training parents and caregivers to manage and promote homebased learning for special children, such as children with disability, illness, and behavioral problems, while learning included promoting reading, playing, eating, and so on.

..."2 health promoting hospitals were responsible for areas in sub-districts. The services included antenatal care and pregnancy examination, caring for postpartum mothers and during breastfeeding period, series of vaccination, monitoring and promoting child development based on the standard of Ministry of Public Health for children aged 2 months and above, child nutritional status (weight measurement) to be assessed every 3 months, IQ/EQ Test (only at the age of 3-5 years), dental health care, and so on..." (Ubon Ratchathani province)

4) Caring from local administrative organizations. These operations were carried out according to the national health security policy through the participation of all sectors in communities. The health security sub-district fund committee was established. There works included formulating sub-district health plans, screening diseases, surveillance of illness, disease prevention and control, evaluation and promotion of development, improvement of caregivers' capability, home visit services, examination of chemical residues in farmer's blood, training community volunteers, and so on.

..."The projects relying on the budget of health security sub-district fund for all sectors, including local administrative organizations, sub-district health promoting hospitals, community leaders, or other groups/community organizations/volunteers, were planned to ensure comprehensiveness, using existing social capitals to assist and monitor health status in order to provide all aspects of caring for children aged 0-5 years, ranging from promoting breastfeeding for the first 6 months, development, nutritional status, and caring for ill children, in a complete and continuous manner (Sa Kaeo province)..."

5) Caring from child development center. The activities it performs include: (1) screening of epidemic diseases or disorders in children; (2) assessing child development; (3) managing learning to enhance experiences and child development by carrying out activities for promoting movement, creativity, outdoor playing, child corner equipped with toys, books, and drawing books, with the emphasis on creating learning materials along with activities for skill and muscle training within the centers and communities.

..." The child care and development center provided learning for early childhood aged 2-3 years so as to promote their physical, psychological, emotional, social, and intellectual development..." (Mae Hong Son province)

6 ) Caring from family development centers and other agencies in communities. The activities related to maternal support and child rearing include: (1) making surveillance, preventing and solving problems, giving advices, and promoting families to learn how to solve problems; (2) coordinating with networks and various agencies for developing understanding of 
families for caring adolescent mothers; (3) training community volunteers to support breastfeeding and caring for pregnant women and postpartum mothers; (4) training poor families to develop skills for caring early childhood; and (5) promoting natural health care for primary care prior to transfer, and so on.

Thirdly, managing social welfare and community funds. These activities were provided by community organizations and government sectors for pregnant women, mothers and children. The performed activities emphasis on encouraging pregnant women, mothers, and family members to join as members of professional groups and community financial institutes. The benefit gaining from membership are savings and social welfares. In this regard, social welfares also included the development of volunteers for mutual assistance, subsidization, saving system, occupation promotion, and assistance in normal and emergency situations. The development of social welfares and funds could be classified into four aspects included: 1) Economic aspect by occupation promotion to create jobs and income, reducing expenses, enhancing learning for families regarding savings and cost reduction, being members of accessible cooperative stores and selling products, forming saving groups to receive assistance in emergency cases and for child rearing, and so on; 2) Health aspect by giving the information on medical privileges, compensation of medical expenses or medical services, welfares for newborns, clean water supply, and waste management; 3) Social aspect with three kinds of services included: (1) normal welfares, such as scholarship welfares, creating volunteer for assisting mothers and children such as reading for children, taking children for exercising and recreation, monitoring and surveillance security in the community by civil defense volunteers, and reconciliation of conflicts by community leaders; (2) emergency services such as transportation services when going to the hospital, home visits, and so on; (3) government welfares by promoting accessibility to rights for subsidy of newborns in troubled families.

Fourthly, development the safe and learning-enhanced environment for pregnant women, mothers, and children aged 0-5 years by establishing two directions of activities included: 1) The development of health-friendly environment along with preserving the environment. This kinds of activities include reducing chemical substance usage, setting up the environment to reduce road accidents, and preventing hazards against children in child development centers, such as preventing and screening diseases in child development centers, healthy food management, campaign and survey on elimination of mosquito larva, and so on; 2) The development of learning-enhanced environment. The relevant activities included allocating the environment at home, in child development centers, agencies, organizations, and sources of benefits in communities, for example, arranging spaces and corners for children, providing toys and books, reading promotion activities, establishing learning centers for preservation of culture and local wisdom, building playgrounds in communities, creating activity areas of child development centers. There were some organizations play direct role in this matter, such as sub- 
district headmen, village headmen, local administrative organizations, community mechanic groups, organic agricultural and healthy food group, schools, breastfeeding promotion centers, child development centers, waste banks, sports clubs, volunteering child and youth groups, tree

..." Schools encouraged children to learn local way of life by providing spaces for children to do plantations and animal farming based on the philosophy of sufficiency economy, as well as cooperating with temples in teaching Buddhism, morality and ethics, while provosts assisted with teaching..." (Nakhon Ratchasima province)

..." Shuttle services were provided from homes to child care and development centers, as well as adjusting environment of child care and development centers..." (Ubon Ratchathani province)

Fifthly, educational services, the community activities for providing educational services for children include: (1) establishing child development centers; (2) establishing local learning centers; (3) establishing elderly schools to have local wisdom learning sources in communities; (4) establishing family development centers to serve as the hub and mechanism for surveillance, as well as preventing and solving problems; (5) providing shuttle services for children; (6) procuring toys and adjusting the environment of child development centers. In this regard, the supports were provided by local administrative organizations, community leaders, and community organizations. As a result, the community way of life learning could bring about value and pride in their own communities, as well as building good relationships between children and communities.

..." Local administrative organizations had procedures for formulating long-term development plan of child care and development centers, ranging from developing capability of teachers, selecting the committee for developing child care and development centers based on the community participation, procuring learning materials, improving physical structures, toys, and food sufficiently and continuously..." (Sa Kaeo province)

..." Child care and development centers in sub-districts issued the manual on standard criteria for learning program..." (Sisaket province)

Sixthly, managing sources of information, this activity performed by community leaders, subdistrict headmen, village headmen, village health volunteers, primary care units, and local administrative organizations by broadcasting useful information and welfares for mothers and children continuously.

Seventhly, caring based on cultural and traditional way, these activities include: (1) caring from religious leaders, such as monks for Buddhism, To-Imams for Islam, and so on. The religious ceremonies were held to enhance confidence for mothering, build relationships and construct warmth in the families, as well as fostering children to speak politely, tell the truth, grow up as 
good people in the society; (2) caring from local philosophers, such as Tok-Bidan or midwife, and folk healer, who provided caring for pregnant women and children aged 0-5 years, such as ensuring best birthing position, delivery of baby, postpartum massage, female circumcision, baby's first haircut, herbal treatment, caring for pregnant women, postpartum women, ill children and so on.

..." Herbal group formed a group for planting herbs, making up herbal compress balls, and providing medicinal bathing after birth. Herbal healers applied local wisdom to taking care of pregnant women before and after birth by using herbs..." (Mae Hong Son province)

..." Boss (alias) aged 1 year was living with grandparents and a sister aged 6 years. Main caregiver was his grandmother. Boss suffered allergic diseases, so he needed to receive continuous treatment. He mostly received treatment from provincial hospitals. In this regard, his grandmother also provided him with traditional treatment by serving him boiling herbs for treatment and relief purposes..." (Nakhon Ratchasima province)

The findings of the study revealed the situations on way of life of pregnant women and women with children, and child rearing among children aged 0-5 years. These circumstances reflected problems and need among mothers and children, social capital and their capabilities under the socio-cultural context, and concrete community self-management for caring mothers and children in each locality. In addition, there are at least four key actors who play important role for developing works and activities for increasing accessibility to essential right and services of mothers, young children, and families. The main four key actors include social group, community organizations, community leaders or localities, and healthcare unit. This would strengthen the community organizations contributing to health development of mothers and children based on changing needs and available resources (Shears, Vatsia, Igras, \& Tipton, 2006). Likewise, cooperation of all related sectors in community based on the participation and ownership principle could be able to strengthen local communities and key agencies in localities to have capability in health development and reduce illness among of mothers and children (Hengboonyaphan \& Nuntaboot, 2017; Kuruvilla et al., 2014).

In term of community managing for enhancing accessibility to essential services and achieving maternal and child need and right, there are seven groups of services were performed namely, 1) managing fundamental rights and services; 2) health services; 3) social welfare and community funds; 4) development of safe and learning-enhanced environment; 5) educational services; 6) managing sources of information; and 7) caring based on cultural and traditional way. These provided services and activities were implemented according to the national policy and requirements in localities comprehensively. The main purposes are achieving at maternal and child need as well as increasing quality of life of mothers and children sustainably. Even though various activities and services are performed through all sectors in community, some maternal need and children right can't be achieved according to some restricted conditions, such as 
privilege mothers, illiterate, and underprivileged children. Especially, some services are effectively implemented in community sections meanwhile the national policy aren't improvement, such as safety food management, adequate exclusive breast feeding, sustainable employment among motherhood, social welfare, adequate family income, and social support for child rearing during early childhood. This issue should be refining by national policy makers in order that the suitable policy would be achieved and essential right of mothers and children could be reached.

Compare the community services to the United Nations Policy on Sustainable Development Goals (United Nations, 2018b) found that those activities particularly support Sustainable Development Goals 1 (no poverty), 2 (nutrition), 3 (good health) and 5 (gender equality). In addition, the impact of those community services result in poverty reduction as well as improved child health and access to social services which comply with the United Nations Convention on the Rights of the Child (UNCRC) and A World Fit for Children declaration (UNICEF, 2008). However, there are some goals couldn't be completely achieved including quality education (Goal 4), clean water and sanitation (Goal 6), decent work and economic growth (Goal 8), and sustainable cities and communities (Goal 11). Therefore, the policy makers and stakeholder can be improving key policy decisions in order that the all mothers and children would be covering.

To evaluate the efficacy of community managing for enhancing maternal and child right, the guideline from two national policies of Thai government are allegorized. To enhance human capacity and long term development of appropriate and timely manner, Ministry of Public Health (2018) announced the 20-year National Strategy which is a long-term plan to develop economics, society, environment, and human resources. Likewise, the Office of the National Economic and Social Development Board (2018) established the Twelfth National Economic and Social Development Plan (B.E. 2560-2564) which placed the emphasis on manpower preparation and capability development of populations of all age groups. Compare the finding upon community managing with these two national plan and strategies illustrate that the right for accessibility to sustainable occupation, stability family income, and social welfare among mothers and family of young children in all social class aren't accomplished. So, the policy makers should be revise and improve long term plan in order to extend the services and program covering in all dimension which will enable increases in long-term productivity.

In term of maternal and child right to access to quality births and development as well as wellbeing, Department of Health (2019) announced the strategy calling "The $2^{\text {nd }}$ National Reproductive Health Development Policy and Strategy (2017-2026)" to promote the collaboration among public sectors, government, and local community. The necessary operations should be including development equality health service system, social welfare, social media and communication. Supported by Office of the Education Council (2007) 
announced that early childhood aged 0-5 years have to promote to be effectively well-rounded developed, and be able to equally access to health services, education, and social welfares. The relevant finding upon community activities partial comply with these strategies include providing proactive services for pregnant women, antenatal care, educating pregnant women and families on health promotion throughout motherhood and early child rearing, and training volunteers to support mothers and children. However, there are some part of essential services should be improved and extended for long-term productivity among mothers and children such as strengthen family capability, developing human capital as the supporter, Thai Women Empowerment Funds, utilization religious and cultural implementation.

With regard to caring for early childhood, Office of the Education Council (2007) operate the Early childhood development plan (2007-2016) aim to develop all of early childhood aged 0-5 years to be effectively well-rounded developed, and be able to equally access to health services, education, and social welfares. For example, establishing child development centers in communities, creating sources of learning in localities, establishing environment in child development centers and communities, and training parents and caregivers are operated. Nevertheless, the lacking of essential nutrition support, continuing breast milk support, community financial institutes, social assistance centers, covering child care development centers should be highlighted and improved immediately.

\section{Conclusion}

The finding indicated that the operations and cooperation between the public sector, private sector, and local community organizations can be providing works and systems for mothers and children to enable them to access to essential rights and services in response to their requirements. However, there are some issue have to concern and improve include increasing the accessibility to essential right and services among privilege mothers, illiterate, and underprivileged children across nationwide. Likewise, some activities and services are effectively provided and operated only in community level regardless of national policy stimulation such as safety food management, adequate exclusive breast feeding, sustainable employment among motherhood, social welfare, adequate family income, essential nutrition support, community financial institutes, utilization religious and cultural implementation, and social support for child rearing during early childhood. This could be implemented by managing conditions of each circumstance and opportunity. In this regard, the public sector, relevant stakeholders, and national policy makers can be utilizing the current results to support decisionmaking, prospective guideline development, and policy-based planning in order that increasing of opportunities and accessibility to essential rights and services of mothers and children comprehensively and sustainably improvement. 


\section{Acknowledgement}

Authors would like to thank the respondents for all valuable data provided in this research.

\section{Conflict of Interest}

There is no conflict of interest in this research result

\section{REFERENCES}

[1] UNICEF. (2008). A world fit for children. New York: UNICEF.

[2] UNICEF. (2011). Situational analysis of children and women in Thailand 2011. Thailand: UNICEF Thailand.

[3] Office of the Education Council. (2007). Policy and strategy for long term early childhood development (2007-2016). Bangkok: V.T.C. Communication. (in Thai).

[4] Secretariat of the House of Representatives. (2004). National Health Security Act, B.E. 2545. Available from:

https://www.parliament.go.th/ewtadmin/ewt/elaw_parcy/ewt_dl_link.php?nid=1836. (in Thai).

[5] Office of the Council of State. (2006). Determining Plans and Process of Decentralization to Local Government Organization Act B.E. 2542 (1999). Available from: http://web.krisdika.go.th/data/law/law2/\%A1100/\%A1100-20-9999update.pdf. (in Thai).

[6] Netgrajang, C., Nuntaboot, K., and Theerasopon, P. (2014). Strengthening child rearing system during early childhood ( $0-5$ years) by the community. Journal of Nursing Science \& Health, 37(4), 83-94.

[7] Jaitieng, A., and Nuntaboot, K. (2018). Community care system for families with children 0-5 years. Suranaree Journal of Science and Technology, 25(2), 201-212.

[8] UNICEF. (2019). Thailand child support grant (CSG) impact evaluation report. Thailand: UNICEF Thailand.

[9] Nuntaboot, K., Boonsawatgulchai, P., Sorakrij, C., Sritragool, R., Sornboon, A., Bubpa, N., and Jaraepraparn, U. (2013). The Manual of Rapid Ethnographic Community Assessment Process: RECAP. Bangkok Thai Health Promotion Foundation, Healthy Community Strengthening Section (Section 3), Development in Community Health Care System, Faculty of Nursing, Khon Kaen University, Khon Kaen, Thailand, 233p. (in Thai)

[10] Shears, K. H., Vatsia, U., Igras, S., \& Tipton, M. (2006). The role of community involvement in improving reproductive health and preventing HIV among young people: report of a technical consultation, November 8-9, 2005. Care Usa. 
[11] Hengboonyaphan, D., and Nuntaboot, K. (2017). Social wisdom: the root of sustainable development. Bangkok Thai Health Promotion Foundation, Healthy Community Strengthening Section (Section 3), Bangkok, Thailand. (in Thai).

[12] Kuruvilla, S., Schweitzer, J., Bishai, D., Chowdhury, S., Caramani, D., Frost, L., ... \& Cohen, R. (2014). Success factors for reducing maternal and child mortality. Bulletin of the World Health Organization, 92, 533-544.

[13] United Nations. (2018b). Transforming our world: The 2030 agenda for sustainable development. New York, NY, USA: United Nations. Available from: https:// sustainabledevelopment.un.org/content/documents/2.

[14] Ministry of Public Health. (2018). The 20-Year National Strategy (Public Health). Nonthaburi, Thailand: Ministry of Public Health. Available from: www.inter. nstda.or.th/stks/pub/2017/20171117-MinistryofPublic Health.pdf. (in Thai)

[15] The Office of the National Economic and Social Development Board. (2018). The Twelfth National Economic and Social Development Plan (B.E. 2560 - 2564). Bangkok, Thailand: National Economic and Social Development Board. Available from: http:// www.nesdb.go.th/ewt_dl_link.php?nid=6422. (in Thai)

[16] Department of Health. (2019). The 2nd National Reproductive Health Development Policy and Strategy (2017-2026) on the Promotion of Quality Birth and Growth. Ministry of Public Health. Available from:

http://rh.anamai.moph.go.th/more_news.php?cid=19\&filename=index. 